\title{
$\underline{\mathbf{P}-73}$
}

\section{Dihydrochalcone from the Leaves of Ellipeia Cuneifolia (Annonaceae)}

\author{
Hasliza Yusof*, Laily B. Din and Wan Yaacob Wan Ahmad
}

School of Chemical Sciences and Food Technology, Faculty of Science and Technology, Universiti Kebangsaan Malaysia, 43600 UKM Bangi, Selangor D.E., Malaysia; E-mail: haslizahjyusof@gmail.com

Three of dihydrochalcone, 2',4'-dihydroxy-4,6'-dimethoxydihydrochalcone (1), 2',4',6'-trihydroxy-4-methoxy-dihydrochalcone (2) and uvangoletin (3), were isolated from the chloroform extract of the leaves of Ellipeia cuneifolia. Purification of the crude extract was carried out by using various chromatographic techniques such as vacuum and column. The structures of these compounds were elucidated based on spectroscopic methods NMR (1D and 2D), LCMS, UV, IR and comparison with the published data. 